\title{
PHYSICOCHEMICAL CHARACTERISTICS, POPULARITY AND SUSCEPTIBILITY TO ANTHRACNOSE OF SOME LOCAL BANANA CULTIVARS
}

\author{
O.D.A.N. PERERA, B.M.K.M.K. BASNAYAKE and ANJANI M. KARUNARATNE" \\ Department of Botany, Faculty of Science, University of Peradeniya, Peradeniya.
}

(Received: 01 June 1998 ; accepted: 09 April 1999)

\begin{abstract}
The physicochemical characteristics, peel thickness, firmness, peel to pulp ratio, $\mathrm{pH}, \%$ titratable acidity (\%TA), and soluble solids content (SSC), were determined in six local cultivars of banana; 'Ambon', 'Embul', 'Kolikuttu', 'Seenikehel', 'Puwalu', and 'Anamalu'. Physicochemical characteristics were comparable to those of some commercially important cultivars in other countries. A tendancy for a positive correlation ( $p \leq 0.1$ ) was observed between pairs of physical parameters (peel thickness, firmness and peel:pulp). The lowest and the highest peel thicknesses were observed in 'Kolikuttu' (1.27 mm) and 'Anamalu' (2.73 mm) respectively. These cultivars also recorded the lowest ('Kolikuttu' $-0.91 \mathrm{~kg} \mathrm{~cm}^{-2}$ ) and the highest ('Anamalu'-2.01 kg cm-2) firmness values. The highest peel to pulp ratio was in 'Anamalu' (0.24) and the lowest, in 'Kolikuttu' (0.09). A significantly lower pH (3.73) and higher \%'TA (10.56) were observed in 'Embul'. The pulp of ripe 'Seenikehel' had a significantly higher SSC (25.58' Brix).

A taste preference study showed that 'Kolikuttu' was the most popular, while 'Embul' and 'Ambon' were preferred second, equally. The least preferred were 'Anamalu', 'Seenikehel' and 'Puwalu'.

Initiation of anthracnose was delayed the most, in 'Puwalu', when conidia of C. musue, from typical anthracnose lesions from 'Anamalu' fruits were inoculated onto ripe fruits of the other 5 cultivars. In 'Puwalu', anthracnose development and spreading of lesions were also comparatively slow. Anthracnose development was most rapid in 'Kolikuttu', which also recorded the lowest firmness and the lowest peel to pulp ratio. The correlation between lesion diameters and each physical parameter was negative without statistical significance.
\end{abstract}

Key words: Bananas, Colletotrichum musae.

\section{INTRODUCTION}

About 22 cultivars of dessert bananas are available in Sri Lanka. ${ }^{1-2}$ Some of these may have a good export potential, either fresh or processed. Most of the commercial banana cultivars grown in Sri Lanka are susceptible to anthracnose causing considerable postharvest losses.

"Corresponding author

A part of this work was presented at the Annual Sessions of the Faculty of Science, University of Peradeniya. 
Globally, the banana trade has mainly centred around the 'Cavendish' type. This though available freely, catering to the tastes of different ethnic groups in industrialized countries has become lucrative business and it is time that a larger choice of banana varieties is introduced to the world.

Having a large collection of locally grown cultivars, Sri Lanka has the potential to offer a variety of new cultivars of banana. Sri Lankan banana cultivars may be comparable to the cultivars grown in the Asian region. There are no records available on physicochemical characteristics and susceptibility to anthracnose by these local cultivars.

This study was an initial attempt to determine some postharvest parameters of six locally popular banana cultivars with the intention of evaluating their potential popularity in the international market. Among the parameters determined were physicochemical attributes, their degree of popularity among Sri Lankans, and the degree of susceptibility to anthracnose (Colletotrichum musae) by five most popular cultivars of banana as a measure of their keeping quality. The preliminary investigations on physicochemical parameters were presented earlier ${ }^{6}$, which helped us decide on parameters to be investigated in the present study. In addition correlation coefficients were calculated between pairs of physical parameters investigated, and between susceptibility to anthracnose and each of the physical parameters.

\section{METHODS AND MATERIALS}

\section{Bananas:}

Six cultivars of dessert bananas grown in Sri Lanka, namely 'Ambon'(AAA), 'Embul' (AAB), 'Kolikuttu' (AAB), 'Seenikehel' (ABB) 'Puwalu' (AAB) and 'Anamalu' (AAA) were used in this study. All bananas were subject to the experiments described below, within 24 h of turning to fully yellow stage. In the case of 'Anamalu' which does not turn yellow with ripening, changing into a lighter green skin colour was used as an estimate for timing of analysis.

\section{Physicochemical characters: \\ Fruit firmness:}

Three $1 \mathrm{~cm}$ thick transverse sections were removed from the pulp of each finger and firmness was recorded by using a hand held penetrometer (Forestry Suppliers Inc., UK) as described. 


\section{Peel thickness:}

Bananas were peeled off and thickness of the peel was measured at three different locations (stylar-end, middle and stem-end) by using a vernier caliper and the average value was determined.

\section{Peel to pulp ratio:}

Three $1 \mathrm{~cm}$ thick transverse sections were removed from the centre of each banana and the diameter of the entire section (i.e. including peel) was taken as $d_{1}$ and the diameter of the pulp was taken as $\mathrm{d}_{2}$. The peel to pulp ratio was calculated as $\left(d_{1}-d_{2}\right) \div d_{2}$.

$p H$ :

A $10 \mathrm{~g}$ sample of the pulp was homogenized in a blender for $2 \mathrm{~min}$. Approximately $1 \mathrm{ml}$ portion of this was removed to determine soluble solids content (SSC). The homogenized pulp was diluted 1:4 (10g in $40 \mathrm{ml}$ water). The $\mathrm{pH}$ of pulp was determined by inserting the electrode of a pH meter (TOA Electronic Ltd; Japan HM 205) to the diluted pulp.

\section{\% Titratable acidity (\%TA):}

Samples $(10 \mathrm{ml})$ of the diluted pulp of which the $\mathrm{pH}$ was determined, were titrated against $0.1 \mathrm{~N} \mathrm{NaOH}$ (in triplicate) in the presence of phenolphthalein as an indicator. The end point was taken as a sudden slight change to pink colour. The $\%$ TA was calculated by the following equation:

$\%$ Titratable acidity $=\frac{\text { volume of } \mathrm{NaOH} \times \mathrm{N} \times 100}{\text { weight equivalant in grams. }}$

Soluble Solids Content (SSC):

The homogenate $(1 \mathrm{ml})$ of pulp, apportioned before determining $\mathrm{pH}$, was centrifuged at $3000 \mathrm{~g}$ for $5 \mathrm{~min}$, and a drop of the clear supernatant was used to measure SSC in degrees Brix ${ }^{8}$ using a hand held refractometer (Leica Model 10430).

Taste preference of cultivars:

Eighty Sri Lankans within the age group of 20 to 55, who were familiar with the taste of all 6 cultivars of bananas i.e. 'Ambon', 'Embul', 'Kolikuttu', 'Seenikehel', 'Puwalu' and 'Anamalu', were asked to record their order of preference for these cultivars, on a scale of 1 to 6,1 indicating the most preferred and 6 indicating the least preferred. If they had equal preference for two or more cultivars of banana, they were asked to give the same rank to them. 


\section{Susceptibility to Anthracnose:}

Preparation of Inoculum of Colletotrichum musae:

C. musae was isolated from over-ripe 'Anamalu' fruits having typical anthracnose lesions. Approximately $2 \times 2 \mathrm{~mm}^{2}$ peels from the growing edge of the lesion were cut. They were surface sterilized in a $1 \% \mathrm{NaOCl}$ solution for $3 \mathrm{~min}$ and transferred onto a sterile filter paper to remove excess $\mathrm{NaOCl} .{ }^{9}$ These sections were then plated on to freshly prepared plates of Cook's No. 2 agar medium. "The colonies of Colletotrichum muscie that grew on these plates were sub cultured on to freshly prepared Cook's No.2 agar plates. These were incubated for 6 days at room temperature (i.e. $28 \pm 2^{\circ} \mathrm{C}$ ).

For preparing conidial suspensions for inoculation to bananas, conidia were harvested by gently scraping off the colonies on the agar plates with a sterile spatula, after adding $10 \mathrm{ml}$ of sterilized $\mathrm{H}_{2} \mathrm{O}$. The suspension was filtered through glass wool. This conidial suspension was adjusted to a concentration of approximately $10^{6}$ conidia $\mathrm{ml}^{-1}$.

\section{Inoculation of fruits:}

Five, $20 \mu \mathrm{l}$ drops of the suspension were placed along the longitudinal axis of each banana using a micropipette, in a single row. A moisture chamber was prepared by lining plastic trays $(40 \times 30 \times 7.5 \mathrm{~cm})$ with moist filter papers and on top of which clean dry, glass petri dishes were arranged to rest the fruits. The fruits were placed on the petri dishes without touching the water, and each tray was covered with a heavy glass plate. The fruits were kept in moist chambers for 24-48 h at ambient conditions.

Susceptibility to anthracnose was measured in terms of time taken for initial disease appearance (indicated by browning of the skin) on the spot of inoculation, and the daily increase in lesion diameter.

\section{Statistical Analysis:}

A randomized complete block experiment design was used in each of the above studies. All experiments (except taste preference study) were repeated 3 times, with at least 5 bananas representing a single cultivar in each trial. The statistical analysis for all of the above tests were performed by using a statistical analysis package. ${ }^{11}$ If the $\mathrm{F}$ value by analysis of variance was significant, a Duncan multiple range test was performed for mean separation. The level of significance for all tests was 0.05 . 
Correlation coefficients ( $r$ ) were calculated between pairs of physical parameters (i.e. peel thickness, firmness and peel to pulp ratio) and also between each physical parameter and disease susceptibility (taking diameters of anthracnose lesions on day 8 after inoculation, on the 5 cultivars tested as a measure) and their statistical significance was determined ${ }^{1.2}$ based on a probability level of $\leq 0.1$.

\section{RESULTS}

The lowest and the highest peel thicknesses were observed in 'Kolikuttu' $(1.27 \mathrm{~mm})$ and 'Anamalu' (2.73mm) respectively (Table 1). The peel thickness of 'Anamalu' and 'Puwalu' did not differ significantly. There was no significant difference between thickness values of 'Embul' (1.67 mm) and 'Seenikehel' (1.69 mm), which were significantly higher than that of 'Kolikuttu'. The highest firmness was observed in 'Anamalu' $\left(2.01 \mathrm{~kg} \mathrm{~cm}^{-2}\right)$ and the lowest, in 'Kolikuttu' $(0.91$ $\mathrm{kg} \mathrm{cm}^{-2}$ ). The highest peel to pulp ratio was recorded in 'Anamalu' (0.24) and the lowest in 'Kolikuttu' (0.09).

A tendancy for a positive correlation (at a significance of $p \leq 0.1$ ) was observed among physical parameters [i.e. peel thickness and firmness (0.73), peel thickness and peel to pulp ratio (0.81), and peel to pulp ratio and firmness $(0.83)$ ]. 'Anamalu' had the highest peel thickness and firmness, and 'Kolikuttu', the lowest (Table 1). The highest and lowest peel to pulp ratios were also recorded by 'Anamalu' and 'Kolikuttu' respectively.

Table 1: Peel thickness, firmness and peel : pulp ratio in 5 different cultivars of banana at fully ripe stage.

\begin{tabular}{lccc}
\hline Cultivar & Peel thickness $(\mathrm{mm})$ & Firmness $\left(\mathrm{kg} \mathrm{cm}^{-2}\right)$ & Peel : pulp \\
\hline 'Ambon' & $2,37^{\mathrm{b}}$ & $1.59^{\mathrm{b}}$ & $0.18^{\mathrm{b}}$ \\
'Embul' & $1.67^{\mathrm{c}}$ & $1.45^{\mathrm{bc}}$ & $0.11^{\mathrm{d}}$ \\
'Kolikuttu' & $1.27^{\mathrm{d}}$ & $0.91^{\mathrm{e}}$ & $0.09^{\mathrm{d}}$ \\
'Seenikehel' & $1.69^{\mathrm{c}}$ & $1.01^{\mathrm{dc}}$ & $0.15^{\mathrm{c}}$ \\
'Puwalu' & $2.71^{\mathrm{a}}$ & $1.28^{\mathrm{cd}}$ & $0.15^{\mathrm{c}}$ \\
'Anamalu' & $2.73^{\mathrm{a}}$ & $2.01^{\mathrm{D}}$ & $0.24^{\mathrm{a}}$ \\
\hline
\end{tabular}

:ab.,.c. Different superscripts in a column denote significant differences $(p \leq 0.05)$ by a Duncan Multiple Range
Test.

The pH values of the ripe pulp of 'Ambon', 'Kolikuttu', 'Seenikehel', 'Puwalu' and 'Anamalu' were not significantly different from each other, but that of 'Embul' was 3.7 and this value was significantly low compared to the other five cultivars 
(Table 2). The highest \%TA of ripe pulp was also shown by 'Embul' (10.56\%). The highest SSC values were from 'Seenikehel' (25.58' Brix) and 'Puwalu' (23.74" Brix) and the lowest was from 'Ambon' (19.67' Brix) (Table 2). There was no significant difference between the SSC values of 'Anamalu' (21.78 Brix) and 'Kolikuttu' (21.86' Brix), and these values varied highly in both these cultivars, indicated by 3 superscript characters following the SSC values (Table 2).

Table 2 : $\quad \mathbf{p H}, \%$ TA and SSC $\left(\right.$ Brix $\left.^{0}\right)$ values of pulp in different banana cultivars.

\begin{tabular}{llll}
\hline Cultivar & $\mathrm{pH}$ & $\% \mathrm{TA}$ & SSC \\
\hline 'Ambon' & $4.68^{\mathrm{a}}$ & $4.55^{\mathrm{b}}$ & $19.67^{\mathrm{c}}$ \\
'Embul' & $3.73^{\mathrm{b}}$ & 10.5 & $20.96^{\mathrm{bsc}}$ \\
'Kolikuttu' & $4.59^{\mathrm{a}}$ & $6.43^{\mathrm{al})}$ & $21.86^{\mathrm{allc}}$ \\
'Seenikehel' & $4.80^{\mathrm{a}}$ & $5.33^{\mathrm{ab}}$ & $25.58^{\mathrm{a}}$ \\
'Auwalu' & $4.50^{\mathrm{a}}$ & $5.93^{\mathrm{ib}}$ & $23.74^{\mathrm{abb}}$ \\
\hline
\end{tabular}

n.b,c, Different superscripts in a column denote significant differences $(p \leq 0 .(05)$ by a Duncan Multiple Range Test.

The highest taste preference was for 'Kolikuttu' (which scored the lowest rank). 'Embul' and 'Ambon' were preferred next, with no significant difference between preferences for them. 'Seenikehel', 'Puwalu' and 'Anamalu' were the least preferred with no significant difference between their preferences (Table $3)$.

Table 3: Taste preference (indicated by scoring on a scale of 1-6, where, 1 indicates most preferred and 6, the least preferred) of banana cultivars tested in this study.

\begin{tabular}{ll}
\hline Cultivar & Median \\
\hline 'Ambon' & $3,25^{\mathrm{l}}$ \\
'Embul' & $2.92^{\mathrm{bcc}}$ \\
'Kolikuttu' & $2.51^{\mathrm{c}}$ \\
'Seenikehel' & $4.32^{\mathrm{a}}$ \\
'Puwalu' & $3.96^{\mathrm{a}}$ \\
'Anamalu' & $3.90^{\mathrm{a}}$ \\
\hline
\end{tabular}

${ }^{n, b, c}$ Different superscripts in a column denote significant differences $(p \leq 0.05)$ by a Duncan Multiple Range Test. 


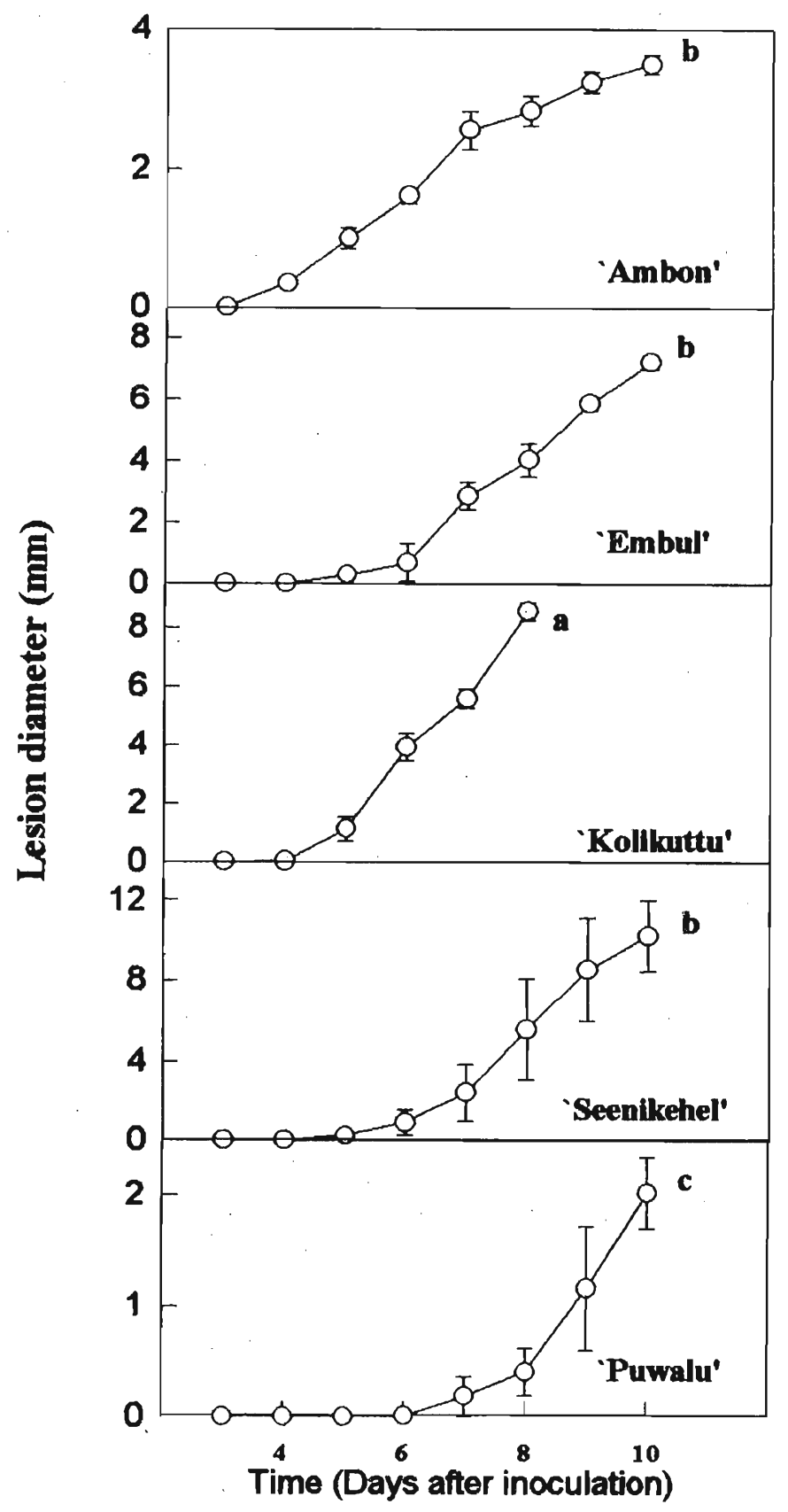

Figure 1 : Anthracnose development in 5 different banana cultivars inoculated with conidia of Colletotrichum musae obtained from typical anthracnose lesions of 'Anamalu'.

Different letters represent significant differences of lesion diameters of day 8 , at $p<0.05$ 
When inoculated with a culture of $C$. musae, initiation of disease was delayed the most, in cultivar 'Puwalu' where anthracnose lesions appeared after the $6^{\text {th }}$ day of inoculation (Fig. 1). Anthracnose development, determined by spreading of the lesion size, was most rapid in 'Kolikuttu'. When lesion sizes at 8 days after inoculation were compared, there was no significant difference $(p \leq 0.05)$ in those of 'Ambon', 'Embul' and 'Seenikehel'. 'Puwalu' recorded the lowest, and 'Kolikuttu', the highest, values being significant at 0.05 level. In 'Kolikuttu', several anthracnose lesions which developed as natural infections merged with the lesions being measured. Therefore lesion diameters in 'Kolikuttu' developing from the inoculated spots could not be measured after 8 days (Fig 1).

The correlation between lesion diameters and each physical parameter was negative (lesion diameter and peel thickness (-0.67), lesion diameter and firmness $(-0.49)$, and lesion diameter and peel to pulp ratio $(-0.59)$. None of these were statistically significant $(\mathrm{p} \leq 0.1)$ (Table 4$)$.

Table 4 : Correlation coefficients (r) among physical parameters and anthracnose lesion diameters, 8 days after inoculation.

Peel thickness $(\mathrm{mm}) \quad$ Firmness $\left(\mathrm{kg} \mathrm{cm}^{-2}\right)$ Lesion diameter $(\mathrm{cm})$

\begin{tabular}{lccc}
\hline Firmness $\left(\mathrm{kg} \mathrm{cm}^{-2}\right)$ & $0.73^{* *}$ & ---- & -0.49 \\
Lesion diameter $(\mathrm{cm})$ & -0.67 & -0.49 & ---- \\
Peel :pulp & $0.81^{*}$ & $0.83^{*}$ & -0.53 \\
\hline
\end{tabular}

All $r$ values followed by * are significant at $p \leq 0.1$.

It was also noted that in 'Kolikuttu', loss of quality occurred due to finger drop and longitudinal splitting of pecl, the former being more frequent than the latter. Approximately $44 \%$ of the bananas used in the present study exhibited finger drop within $72 \mathrm{~h}$ of turning fully yellow. Both these phenomena always occurred after the fruits turned fully yellow.

\section{DISCUSSION}

It is recorded that the relative firmness of the banana fruit is greatly determined by physical and chemical attributes such as peel thickness and starch content. ${ }^{12}$ In the present study too a positive correlation between peel thickness and firmness $(r=0.73$, $\mathrm{p} \leq 0.1$ ) was observed.

Peel thickness and peel to pulp ratio, as well as firmness and peel to pulp ratio indicated a tendancy for positive correlation with $\mathrm{p} \leq 0.1$ (Table 4 ). The higher peel to pulp ratio and the thicker peel probably contributed to the higher firmness of Anamalu (Table 1). 
The highest and lowest sugar levels (inferred by the SSC) were recorded by 'Seenikehel' and 'Ambon' respectively. It was observed that the SSC value of 'Kolikuttu' did not differ significantly from that of 'Ambon', as the variation of SSC in 'Kolikuttu' was higher (Table 2). The pH value of the ripe pulp of 'Embul' was significantly low (3.73) while this cultivar had the highest \%TA (10.56) (Table 2).

Although, the physicochemical characteristics (given in table 2) are reported to contribute to taste ${ }^{14}$ a major contribution to flavour would be by volatile components. It was beyond the scope of this study to determine volatile components of the different cultivars. However, the results of the taste preference study was expected to compensate to a certain degree for this shortcoming.

'Anamalu' which had a low preference in this study is recorded to be indigenous to Sri Lanka and shows resemblances to 'Gros Michel'. 'Although small quantities have been exported intermittently in the past, Gros Michel is not recorded as a commercially important cultivar. ${ }^{15}$ Besides, the green peel colour when ripe, of 'Anamalu' may not be very appealing to the discriminating, affluent buyer, who would pay more for good quality produce. Moreover, 'Anamalu' did not excel in any of the physicochemical characteristics tested (Table 2) which may partially contribute to taste, and its peel to pulp ratio was the highest which indicates that there is a higher percentage of the unusable peel.

'Anamalu' was not included in determining susceptibility to anthracnose as the C. musae isolates for this study were obtained from anthracnose lesions of' 'Anamalu' fruits. 'Anamalu' was chosen for this purpose, as it ranked lowest in the taste preference study (Table 3) and is an unlikely candidate to compete in the international market for reasons given above.

Although none of the correlation coefficients between lesion diameters and each of the physicochemical parameters were significant, the strongest relationship among them was between peel thickness and lesion diameters, with $r=-0.67$ (Table 4). 'Kolikuttu' recorded the largest lesion diameters (Fig 1) and had the least thickness (and firmness) of peel. (Table 1). 'Puwalu' recorded the smallest lesion diameters and had the thickest peel (excluding 'Anamalu' which was not tested for disease). Of both 'Puwalu' and 'Seenikehel', the latter had larger lesion diameters and significantly thinner peel, although both had identical peel to pulp ratios (Table 1). 'Embul' on the other hand, was significantly less susceptible to anthracnose although it recorded the lowest peel thickness value which was not significantly different from that of 'Seenikehel' (Fig 1).

If the three-dimensional spreading of the disease was noted, instead of the lesion diameters, it is possible that the negative trend between peel thickness and disease observed in this study would not exist. Yet, having a thicker peel may be advantageous as there is a delay in the disease being visible, and its spreading to the pulp would also be delayed. 
Several authors have compared local banana cultivars with those in other countries. 13,16,17 'Ambon' which ranked second to 'Kolikuttu' in our taste preference study is reported to be the most important cultivar in Indonesia and is said to rank highly in Malaysia.

Considerable similarities were observed, when \%TA and SSC values in this study were compared with different cultivars of commercially popular banana in the South East Asian countries. For instance, \%TA value for the ripe pulp of 'Puwalu' (5.93\%) compared with that of cultivar 'Pisang Kepok' (6.14\%) which is recorded as the most important cultivar in Indonesia and it was similar to the cultivar 'Saba' of Philippines, 'Pisang Nipah' of Malaysia and 'Kluai Hin' of Thailand'". Similarly SSC value obtained for ripe pulp of 'Ambon' (19.67) was close to the value of the cultivar 'Latundan'(20.0). ' However, 'Latundan' has also been compared with 'Kolikuttu'. 'The SSC value for ripe pulp of 'Seenikehel' (25.6), which was the highest among the 6 cultivars, was comparable to that of cultivar 'Pisang Kepolk' (23.9) of Indonesia, which is recorded to have a high level of SSC. ${ }^{19}$

'Embul' appears presently to be the best suited to the export market than 'Kolikuttu'. Its higher resistance to anthracnose is an added advantage to preference. It is recorded to have a high export potential in the European market.

The potential of less popular bananas to be processed or marketed as vegetables need further investigation. Equivalents of 'Seenikehel' in other countries are recorded to be most widely grown and common in those countries and in Thailand it is recorded to be eaten fresh or cooked. ${ }^{17}$ Therefore it may be possible to popularize this cultivar as a vegetable than a fruit. Furthermore, its high sugar content may make it suitable as dried ingredients in desserts, snacks, etc., or processed as flakes or purees.

The results obtained from this study show that some local cultivars may compete well with commercially important bananas. Further studies are necessary to improve keeping quality of locally popular bananas, such as 'Kolikuttu', with emphasis on developing resistance to anthracnose. Although this was the most popular cultivar, it was very susceptible to anthracnose. In addition, fully ripe fruits were susceptible to finger drop and less frequently to longitudinal skin splitting.

\section{Acknowledgement}

Grant No. E-2110 from the International Foundation for Science in Sweden is gratefully acknowledged. 


\section{References}

1. Chandraratne M.F. \& Nanayakkara K.D.S.S. (1951). Cultivated varieties of banana in Ceylon. Tropical Agriculturist, Ceylon 107:1-22.

2. Fonseka, R.N. de \& Vinasithamby (1971). A provisional index to the local names of the flowering plants of Ceylon. Department of Botany, University of Ceylon, Peradeniya. pp. 108-109.

3. Adikaram N.K.B. (1986-87). A survey of postharvest losses in some fruits and vegetables and the fungi associated with them. Ceylon Journal of Science (Biological Science) $\mathbf{1 9}$ and 20: 1-10.

4. de Costa D.M., Ameradasa B.S. \& Wegiriya R.N.B.P.M.R.C.L. (1997). Antagonists of Colletotrichum musae associated with banana fruit skin. Journal of the National Science Council of Sri Lanka 25(2): 95-104.

5. Perera N. \& Karunaratne A. M. (1995). A study of some peel characteristics of five local varieties of banana, and non-pesticidal chemicals that promote resistance to postharvest diseases. Proceedings Sri Lanka Association for the Advancement of Science $\mathbf{5 1}$ (1) Abs. pp. 68-70

6. Basnayake B.M.K.M.K., Perera O. D. A. N. \& Karunaratne A. M. (1997). A comparative study of some physicochemical parameters of five varieties of banana. Research Session 1996. Faculty of Science, University of Peradeniya. (abstract) p. 8

7. Hewage K.S. (1996). Factors influencing postharvest longevity of Embul bananas. Ph.D thesis, Wye College, University of London.

8. Ratanachinakorn B., Klieber A \& Simons D.H. (1997). Effect of short-term controlled atmospheres and maturity on ripening and eating quality of tomatoes. Postharvest Biology and Technology 11: 149-154.

9. Prusky D., Fuchs Y. \& Yanko U. (1983). Assessment of latent infection as a basis for control of postharvest disease of mango. Plant Disease 67 : 816-818.

10. Chakravarty T. (1957). Anthracnose of banana (Gloeosporium musarum Cke \& Massee) with special reference to latent infection in storage. Transactions of British Mycological Society 40: 337-345. 
11. SAS (1987). SAS user's guide: Statistics, Version 6. SAS Institute Inc., Cary, USA

12. Clarke G.M. \& Cooke D. (1995). A basic course in statistics. Third Edition. Edmundsbury Press, UK. pp. 339-334.

13. Howes F.N. (1928). The banana in some tropical eastern countries - its forms and variations. News Bulletin-Miscellaneous Information : 305-352.

14. Lizada M.C.C., Pantastico Er. B., Shukor A. R. Abd. \& Subari S.D. (1990) Changes during ripening of banana In: Banana fruit development, postharvest handling and marketing in ASEAN (Ed. A. Hassan \& Er. B. Pantastico) Kuala Lumpur, ASEAN Food Handling Bureau. pp. 65-72.

15. Seymour G.B. (1993). Banana. In: Biochemistry of fruit ripening (Eds. G. Seymour, J. Taylor \& G. Tucker). Chapman \& Hall, London. pp. 83-106

16. Simmonds N.W. (1976). Bananas. Second Edition, Longmans, London.

17. Valmayor R.V., Silayoi B., Jamaluddin S.H., Kusumo S., Espino R.R.C. \& Pascua O.C. (1990). Commercial banana cultivars in ASEAN In: Banana - fruit development, postharvest handling and marketing in ASEAN. ( Ed. A. Hassan \& Er. B. Pantastico) Kuala Lumpur, ASEAN Food Handling Bureau. pp. 23-32.

18. Montenegro E.M. (1988). Postharvest behaviour of banana (Musa sp. cv. Latundan ) harvested at different stages of maturity, BS thesis, Laguna: UPLB, Phillipines.

19. Valmayor R.V. (1986). Banana improvement imperatives, the case for-Asia. ACIAR Proceedings No.21 Banana and plantain breeding strategies. Proceedings of an International workshop held at Cairns Australia, 13-17 October 1986 pp. 50-56.

20. Adikaram N.K.B. \& Abayasekera, C.L. (1993). Banana: production, marketing etc. Report submitted to The Federation of Exporters Associations of Sri Lanka. pp:14-20. 